\title{
MESIN TETAS TENAGA SURYA PADA PETERNAKAN ITIK ALABIO DI KECAMATAN GAMBUT KABUPATEN BANJAR
}

\author{
Achmad Jaelani ${ }^{1}$, Neni Widaningsih ${ }^{1}$, dan Muhammad Firman ${ }^{2}$ \\ ${ }^{1}$ Fakultas Pertanian, Universitas Islam Kalimantan \\ ${ }^{2}$ Fakultas Teknik, Universitas Islam Kalimantan \\ Email : ach_jaelaniborneo@yahoo.com
}

\begin{abstract}
Breeding ducks Alabio not be separated from the activities of the hatch, but the productivity in generating Day Old Duck (day old ducklings) on hatching activity remains low. This is due to some problems in the hatchery that often the death of the electricity so that the temperature and humidity of the incubator is not constant during hatching. This will affect the duck embryonic development. Besides, reversal and provision of high humidity is still done manually so that the eggs are often removed from the incubator. Reversal of eggs is essential to prevent embio attached to the shell. South Kalimantan is a tropical region with year-roundsunshine. It can be stored to be utilized as a source of energy through the conversion of solar energy into heating the incubator. Aside from the use of solar energy becomes a substitute for the electricity and can last up to 15 years without having to pay subscription fees and usage of electricity. Solar power conversion technology can overcome the limitations of the heater in the incubator in the District Peat Banjar district, in addition to the modifications to the reversal of eggs and automatic sprayer. With this expected productivity hatchery to produce DOD will be higher. Yet another obstacle arises when DOD high productivity being offset by marketing efforts. For that partners business group sales of poultry Setia Budi prepared to be a partner in marketing the Day Old Duck (DOD), which previously only market the consumption of duck eggs. Measuring the success of this activity is to look at the operation of the incubator solar power during the 28 days prior to hatching without any outages, as well as the percentage of eggs that hatch, number of DOD that hatch in a healthy condition, business analysis more efficient hatching and the number of DOD that could be marketed.
\end{abstract}

Keywords: hatching machine, solar power, Duck Egg Alabio

\section{PENDAHULUAN}

Energi surya merupakan energi yang tidak terbatas dan pemanfaatannya tidak berbayar. Sudah banyak pemanfatan energi surya ini terutama untuk pemanas air dan penerangan jalan umum.
Kecamatan Gambut Kabupaten Banjar merupakan daerah di wilayah tropis yang masyarakatnya sebagian besar hidup dari pertanian dan peternakan terutama peternakan Itik Alabio. Adapun usaha peternakan itik Alabio berupa penjualan 
telur konsumsi, namun untuk usaha pembibitan itik masih sangat sedikit. Sehingga dibutuhkan terobosan diversifikasi usaha agar mengurangi persaingan usaha dan menciptakan lapangan usaha baru, berupa pembibitan yang dikhususkan pada penetasannya. Selama ini penetasan yang dilakukan adalah dengan menggunakan induk entog yang memiliki keterbatasan dalam jumlah telur yang bisa ditetaskan. Adapun solusinya adalah dengan pembuatan mesin tetas. Adapun sumber panas yang digunakan dalam mesin tetas bisa sumber listrik, gas dan lampu teplok.

Wilayah Kecamatan Gambut termauk mlokasi peternakan itik Alabio ini belum seluruhnya terjangkau listrik, sehingga dengan pemanfaatan tenaga surya ini akan mengatasi permasalahan pemanas mesin tetas dan penerangan rumah, Serta bisa mengurangi biaya listrik PLN. Dengan hal tersebut perlu konektivitas antara mesin tetas dengan panel surya agar bisa digunakan. Untuk itu kita perlu menghitung berapa kebutuhan energi untuk operasional mesin tetas selama 28 hari penetasan serta menghitung biaya yang diperlukan dalam usaha penetasan menggunakan tenaga surya ini

\section{METODOLOGI KEGIATAN}

\section{Alat dan Bahan}

1. Perangkat Mesin tetas otomatis yang meliputi Mesin tetas kapasitas 200 butir, Termostat, rak pemutar otomatis, sprayer, pemanas, nampan,Termometer-

hygrometer.

2. Perangkat Tenaga surya yang meliputi : panel surya, converter, inverter, accu

3. Telur tetas 200 butir

\section{Pelaksanaan :}

\section{A. Pembuatan Mesin Tetas Otomatis}

Mesin tetas memiliki Kapasitas mesin 200 butir, dengan system otomatis pada pengaturan suhu, pembalikan dan penyemprotan uap air. Tenaga listrik DC yang diperlukan, dihitung untuk menyesuaikan dengan panel solar yang akan dipasang.

\section{B. Pembuatan Rangkaian Panel Solar Sel}

Rangkaian tenaga surya dipasang sesuai kebutuhan daya pada operasional mesin tetas.

\section{HASIL DAN PEMBAHASAN}

Pada permulaan perakitan mesin tetas, diperoleh bahwa kapasitas mesin tetas diperlihatkan pada tabel 1. 
Tabel 1. Spesifikasi mesin Tetas Tenaga Surya

\begin{tabular}{|c|c|c|}
\hline No & Klasifikasi & Ukuran \\
\hline 1 & $\begin{array}{ll}\text { Dimensi : } \\
\text { a. } & \text { Panjang } \\
\text { b. } & \text { Lebar } \\
\text { c. } & \text { Tinggi } \\
\text { d. } & \text { Volume } \\
\text { e. } & \text { Tinggi dari lantai }\end{array}$ & $\begin{array}{c}70 \mathrm{~cm} \\
60 \mathrm{~cm} \\
50 \mathrm{~cm} \\
0,21 \mathrm{~m} 2 \\
40 \mathrm{~cm}\end{array}$ \\
\hline 2 & Kapasitas & 200 butir \\
\hline 3 & Pemanas & $\begin{array}{l}\text { Lampu pijar } \quad \text { (6) @ } 5 \text { watt dan elemen 50 } \\
\text { watt }\end{array}$ \\
\hline 4 & Lubang ventilasi & $\begin{array}{l}\text { Kiri kanan lubang kecil (10) } \\
\text { Atas :Lubang besar }\end{array}$ \\
\hline 5 & Dinding & Triplek 2 lapis \\
\hline 6 & Siku & Alumunium \\
\hline 7 & Rak Setter (pengeraman) & $\begin{array}{l}\text { Kawat Ram Alumunium dengan Roller } \\
\text { pembalikan tiap } 3 \text { jam }\end{array}$ \\
\hline 8 & Sprayer & Otomatis tiap 3 jam \\
\hline 9 & Termostat & Digital otomatis \\
\hline 10 & Nampan air & 2 buah ukuran $37 \times 22 \mathrm{~cm}$ \\
\hline 11 & Suhu $(\mathrm{oC})$ & Min. $38 \circ \mathrm{C}$ \\
\hline 12 & Kelembaban (\%) & $75-85 \%$ \\
\hline
\end{tabular}

Adapun untuk daya listrik yang digunakan dalam mesin tetas tenaga surya adalah sebagaimana tertera pada Tabel 2 .

Tabel 2. Pengukuran daya listrik mesin tetas tenaga surya

\begin{tabular}{|l|l|c|}
\hline No & Komponen Mesin Tetas & Daya (watt) \\
\hline 1 & Termostat & 15 \\
\hline 2 & Sprayer & 10 \\
\hline 3 & Roller rak telur & 30 \\
\hline 4 & Pemanas listrik & 40 \\
\hline Jumlah & 95 \\
\hline
\end{tabular}

Pada tabel 2 terlihat bahwa jumlah daya yang diperlukan adalah 95 watt (dibulatkan menjadi 100 watt),sehingga dengan jumlah daya sebesar ini akan dihitung berapa kebutuhan komponen solar selnya.
A. Perhitungan penggunaan panel tenaga surya

\section{Penentuan Besarnya Daya Yang Terpakai Perhari}

Jumlah daya yang terpakai per harinya disajikan pada tabel 3. 
Tabel 3. Perhitungan daya yang terpakai

\begin{tabular}{|l|l|c|c|c|r|c|}
\cline { 4 - 6 } No & Nama barang & Unit & $\begin{array}{c}\text { Daya } \\
\text { (watt) }\end{array}$ & $\begin{array}{c}\text { Tegangan } \\
\text { (volt) }\end{array}$ & Jam/hari & $\begin{array}{c}\text { Total daya } \\
\text { watt jam } \\
(\mathrm{W} / \mathrm{h})\end{array}$ \\
\hline 1 & $\begin{array}{l}\text { Mesin Tetas } \\
\text { Tenaga surya }\end{array}$ & $1 \mathrm{x} @ 100 \mathrm{~W}$ & 100 & 220 & 24 & 2400 \\
\hline \multicolumn{2}{|l|}{ Jumlah daya } & & & 2400 \\
\hline
\end{tabular}

Dari data tersebut didapatkan

Kuat Arus ( I ) $=2880 \mathrm{Wh} / 12 \mathrm{~V}=240$

keperluan daya listrik yang terpakai perharinya adalah sebesar $2200 \mathrm{Wh}$. Daya Amperjam ( Ah ). listrik terpakai perhari sebesar $2400 \mathrm{Wh}$ perlu ditambahkan sekitar 20 persen untuk digunakan oleh perangkat selain panel surya, yaitu inverter sebagai pengubah arus DC (searah) menjadi AC (bolak - balik) karena pada umumnya peralatan menggunakan arus AC dan controller (sebagai pengatur arus) yakni menutup arus ke baterai jika tegangan sudah berlebih di baterai dan memberhentikan pengambilan arus dari baterai jika baterai sudah hampir kosong. Jika ditambahkan 20\%, maka total daya listrik terpakai perharinya yang dibutuhkan menjadi:

Total Daya listrik terpakai perhari $=2400$ $+(2400 \times 20 \%)=2880 \mathrm{Wh}$.

\section{Menghitung Kebutuhan Baterai}

Dari $2.880 \mathrm{Wh}$ tersebut, jika dibagi dengan tegangan $12 \mathrm{~V}$ (tegangan umum yang dimiliki baterai) maka kuat arus yang dibutuhkan adalah:

Jika kita menggunakan baterai yang kapasitasnya sebesar 100 Ah 12 V, maka kita membutuhkan: Jumlah baterai $=240$ $\mathrm{Ah} / 100 \mathrm{Ah}=2,4$, kita tetapkan menjadi Tiga ( 3 ) baterai. Maka jumlah daya yang dihasilkan baterai $=100 \mathrm{Ah} \times 12 \mathrm{~V} \times 3=$ $3600 \mathrm{Wh}$.

\section{Menghitung Kebutuhan Panel Surya}

Dengan mengetahui jumlah daya yang dihasilkan baterai sebesar $3600 \mathrm{Wh}$, kita akan mendapatkan jumlah panel yang kita butuhkan, termasuk besarannya yakni sebagai berikut: Pada perancangan ini panel surya yang digunakan mempunyai kapasitas 100 Watt Peak (WP), jika dalam satu hari mendapat penyinaran matahari selama 5 jam ( 5 jam didapat dari efektivitas rata- rata waktu sinar matahari bersinar di negara tropis seperti Indonesia, dan 5 jam ini sudah menjadi semacam perhitungan rumus baku efektivitas sinar matahari yang diserap 
oleh panel surya ), maka panel surya ini mampu mensuplai daya listrik sejumlah:

Daya listrik yang mampu di suplai $=100$

Watt $\times 5$ Jam $=500$ Wattjam $(\mathrm{Wh})$

Jika 1 panel surya dengan kapasitas 100

Wp mampu menghasilkan listrik sebesar

500 Wattjam (Wh ), maka akan kita

dapatkan total panel yang dibutuhkan

adalah:

Total panel surya $=3600 \mathrm{Wh} / 500 \mathrm{Wh}=$

\section{Menghitung Solar Charge}

\section{Controller}

Untuk menghitung kebutuhan solar charge controller, maka kita harus mengetahui dulu karakteristik dan spesifikasi dari panel surya, biasanya pada panel surya terdapat spesifikasi seperti disajikan pada table 4 sebagai berikut

7,2 atau 8 panel.

Tabel 4. Spesifikasi Solar Charge Controler

\begin{tabular}{|c|l|c|}
\hline \multicolumn{1}{l|l}{ No } & Spesifikasi & Besaran \\
\hline 1 & Maximum Power ( Pm) & $100 \mathrm{Wp}$ \\
\hline 2 & Optimum Power Voltage (Vmp) & $22,70 \mathrm{~V}$ \\
\hline 3 & Optimum Operation Current (Imp) & $4,39 \mathrm{~A}$ \\
\hline 4 & Open Circuit Voltage (Voc) & $29,13 \mathrm{~V}$ \\
\hline 5 & Short circuit current (Isc) & $3,30 \mathrm{~A}$ \\
\hline 6 & Backig (Brand Type) & BELL \\
\hline 7 & Jenis & Monocristalin \\
\hline 8 & Kuat arus kontroler & $26,4 \mathrm{~A}$ \\
\hline
\end{tabular}

Dari spesifikasi yang telah kita

ketahui yang harus diperhatikan adalah angka Isc (short circuit current), yang mana nilainya akan kita kalikan dengan jumlah panel surya, sehingga hasilnya merupakan nilai minimal dari charge controller yang dibutuhkan. Disini kita menggunakan 8 panel surya $100 \mathrm{Wp}$, yang dipasang paralel maka kita akan butuh kontroler yang mempunyai kuat arus:

3,30 A x $8=26,4$ A. Maka sebaiknya kita gunakan contoler yang $30 \mathrm{~A}$ agar lebih aman.

\section{Menghitung Inverter}

Spesifikasi inverter harus sesuai dengan tegangan kerja dari sistem dan tegangan pada beban AC, beberapa inverter memiliki kemampuan efisiensi 
daya yang berbeda-beda dari daya maksimum yang hasilkan. Maksud dari efisiensi daya tersebut adalah besaran daya sesungguhnya (murni) yang dapat serap atau dipakai untuk konsumsi/ pemakaian beban. Dan inverter yang baik adalah inverter yang mampu menghasilkan efisiensi tinggi (sekitar $85 \%$ - 90\% ke atas) dari besar daya yang maksimum. misalnya inverter dengan kapasitas 1000 watt dengan efisiensi 90\%, artinya dari kemampuan daya maksimum inverter sebesar 1000 watt tersebut, batas maksimum daya yang dapat dipakai adalah sebesar 900 watt saja. (90\% dari 1000 watt).

\section{B. Operasional Mesin Tetas}

Sebelum mesin tetas digunakan, terlebih dahulu mesin tetas dilakukan pembersihan dengan menggunakan desinfektan agar membunuh bibit penyakit yang dapat mengganggu jalannya penetasan.

Untuk pengoperasian mesin tetas tenaga surya ini, sebelumnya dilakukan stabilitas suhu selama 2 hari. Adapun suhu yang dipatok untuk penetasan ini adalah 38 - 38.5oC. Disini terlebih dahulu thermostat digitaldi setel pada angka tersebut. Apabila suhu melebihi batas maksimal, maka lampu pemanas akan padam.

Pemutaran telur dilakukan seting untuk setiap 3 jam mengalami pergerakan (Roller berjalan) sehingga rak telur bergerakyang diikuti pergerakan telur. Pergerakan telur ini dilakukan mulai hari ke 5 setelah perlakuan candling (peneropongan) untuk memisahkan mana telur yang fertile dan yang tidak fertile. Dari hasil penetasan telur yang di candiling ternyata dari 200 butir telur yang masuk, yang infertile sebanyak 12 butir atau sebanyak $6 \%$ yang infertile atau 188 butir yang fertile sehingga diketahui 94\% daya fertilitasnya. Untuk telur yang kosong/infertile dikeluarkan dari mesin tetas. Untuk telur yang kosong/infertile dikeluarkan dari mesin tetas.ulai hari ke-6 dilakukan masa pengeraman sampai hari ke 28. Pada hari ke 28 jumlah telur yang menetas 136 butir. Sehingga daya tetas mesin adalah $73 \%$.

\section{KESIMPULAN DAN SARAN KESIMPULAN}

1. Mesin tetas tenaga surya merupakan teknologi tepat guna untuk peternak pembibitan itik yang memilik kendala dalam hal penggunaan listrik PLN 
2. Teknologi konversi tenaga surya menjadi pemanas mesin tetas mampu menggantikan listrik PLN untuk 28 hari penetasan telur itik Alabio

3. Kebutuhan komponen tenaga surya untuk penetasan itik Alabio dapat disesuiakan dengan jumlah daya yang dipakai selama penetasan.

4. Penetasan dengan tenaga surya mampu menetaskan telur itik alabio hingga 73 persen dari telur yang fertile.

\section{SARAN}

1. Untuk menghindari kekurangan daya yang dapat dikumpulkan dalam batere akibat cuaca hujan, maka perlu penambahan batere.

2. Perlu perawatan panel surya yang intensif agar masa operasional alat panel surya bisa optimal.

\section{DAFTAR PUSTAKA}

Brahmantyo, B dan L. Prasetyo. 2002. Pengaruh bangsa itik Alabio dan Mojosari terhadap performan reproduksi. Proc. Lokakarya Unggas Air. Bogor, 6-7 Agustus 2001. hlm. 73-78.

Dinas Peternakan Kalimantan Selatan. 2004. Buku Saku Peternakan.
Dinas Peternakan Kalimantan Selatan. Banjarbaru.

Ditjenak. 1998. Kumpulan Standar Nasional Indonesia Sub Sektor peternakan Jilid I. Jakarta.

Istiana, Suryana dan Tarmuji. 1991. Sanitasi pada beberapa tempat penetasan itik dan lingkungannya di Kabupaten Hulu Sungai Utara, Kalimantan Selatan. Penyakit Hewan 23(42): 16-18.

Juarini, E. dan Sumanto. 2000. Model usaha itik lokal di D.I. Yogyakarta untuk menunjang pendapatan peternak. Proc. Seminar Nasional Peternakan dan veteriner. Puslitbangnak Bogor.

Lasmini, A.R. dan R. Abdelsamie dan N.M. Parwati.1992. Pengaruh cara penetasan terhadap daya tetas telur itik Tegal dan Alabio. Pros.Pengolahan dan Komunikasi Hasil-hasilPenelitian. Unggas dan Aneka Ternak. Bogor, 20-22 Pebruari 1992. pp. 31-34.

Nawhan A, 1991. Usaha Peternakan Itik Alabio di Kalimantan Selatan. Pidato Ilmiah. Universitas Islam 
Kalimantan. Fakultas Pertanian, Jurusan Peternakan. Banjarbaru

Romanoff, A.L. and A.J. Romanoff. 1963. The Avian. 2 nd ed. John Wiley and Sons, Inc. New York.

Rohaeni, E.S. Istiana dan Tarmuji. 1994. Penetasan itik Alabio di Kalimantan Selatan ditinjau dari aspek manajemen dan kesehatan anak itik yang dihasilkan. Penyakit

Hewan XXVI(47), Semester I. Tahun 1994 pp. 63-68.

Rohaeni, E.S., A.R. Setioko, Istiana dan Darmawan. 2000. Pengembagan Usaha Peternakan Itik Alabio di Kalimantan Selatan Melalui Seleksi. Laporan Akhir. Instalasi
Penelitian dan Pengkajian Teknologi Pertanian Banjarbaru. Setioko, A.R.1992. Teknik penetasan telur itik. Makalah Temu Tugas dalam Aplikasi Teknologi Bidang Peternakan. Pusat Perpustakaan Pertanian dan Komunikasi

Penelitian. Badan Litbang Pertanian. hlm. $142-152$.

Stadelmen, W.J. and P.J. Cotteril. 1977. Eggs Science and Tecnologi. 2 nd ed. The Avi Publishing Company Inc. West Port, Connecticut.

Wasito dan E.s. Rohaeni. 1994. Beternak Itik Alabio. Kanisius. Yogyakarya.

Yuwanta, T. 1983. Beberapa Metoda Praktis Penetasan Telur. Fakultas Peternakan,

UGM 